\title{
Fitness of public health laboratory in the Republic of Macedonia for the application of standards for quality
}

\author{
Evgenija Kiroska-Petreska ${ }^{1}$, Katja Popovska ${ }^{2}$, Vesna Kostikj ${ }^{1}$, Dragan Gjorgjev ${ }^{1}$ \\ Branka Petrovska ${ }^{1}$ \\ ${ }^{1}$ Institute for Public Health of Republic of Macedonia, Skopje, Republic of Macedonia \\ ${ }^{2}$ Institute of Microbiology and parasitology, Faculty of Medicine, University “Ss Cyril and Methodius”, Skopje, Republic of Macedonia \\ Email address: \\ ekakp@yahoo.com (E. Kiroska-Petreska)
}

To cite this article:

Evgenija Kiroska-Petreska, Katja Popovska, Vesna Kostikj, Dragan Gjorgjev, Branka Petrovska. Fitness of Public Health Laboratory in the Republic of Macedonia for the Application of Standards for Quality. Science Journal of Public Health.

Vol. 2, No. 3, 2014, pp. 229-233. doi: 10.11648/j.sjph.20140203.25

\begin{abstract}
The main goal of this master's study is to determine preparedness of public health laboratories concerning the conditions (area, equipment, and staff) and in relation to quality standard application, with identification of the current condition of laboratories in relation to the area, equipment and staff as well as quality standard application in the Institute and the Public Health Centres in the Republic of Macedonia. This research was conducted through a Questionnaire, which was adapted from the ISO/IEC 17025:2005 standard and modified for the goals of the study. Total 144 employees completed the Questionnaire which they were given during the survey (face to face method), with the aim of reducing possible errors. Statistic processing was conducted through application of standard descriptive analyses of quality indicators and check of the hypotheses put forward. The study identified that globally, the preparedness of public health laboratories in the Republic of Macedonia in relation to conditions (area, equipment and staff), for quality standard application, is seen as PARTIAL. The current condition of laboratories in relation to the area, equipment and staff, as well as quality standard application in the Institute and the Public Health Centres in the Republic of Macedonia varies and differs significantly between accredited and non-accredited public health laboratories. In the accredited public health laboratories in the RM, interviewed employees in the Public Health Institute of the RM showed best knowledge and dedication for quality system maintenance in testing laboratories. One can distinguish essential differences in the management staff's view and knowledge in relation to introducing quality systems between managers - health professionals and managers - economists. Testing laboratories in the Institute of Public Health of the RM and few Public Health Centres have adequate and modern equipment, in line with the testing methods, great inadequacy of space in relation to its distribution, non-permitted access, cleanliness and monitoring the ambiance conditions. Professional and competent staffs work in the Institute and in all Public Health Centres, in particular when it comes to testing activities. Motivation of staffs instigated by management teams is what is missing. Both internal and external trainings of staffs are necessary.
\end{abstract}

Keywords: Accreditation, Standards, Testing laboratory, Quality Management System, Technical Requirements

\section{Introduction}

Institute of Public Health of the Republic of Macedonia coordinate and work closely with 10 regional Centers for public health in relation to the monitoring and detection of hazards to human health arising from environmental and food. Quality management in the world experienced major changes, especially in the last decade. [1] These changes primarily relate to the different attitude towards quality requirements of customers. [2] Because these requirements are based on standards ISO 9001 (QMS), ISO 17025
(QM/QA), ISO 15189 (QM/QA) and other models of standards for quality management (QM), in various industries, as well as models to demonstrate of technical competence. This paper presents a public health laboratories, in terms of equipment, facilities and personnel of the models for QM/QA laboratories, and the efforts of managers-doctors and managers-economists for implementation of quality standards, according to the requirements of the latest versions of the standards:

- ISO / IEC 17025:2005-General Requirements for the Competence of Testing and Calibration Laboratories 
(General requirements for the competence of testing and calibration laboratories); [3]

- ISO 15189:2007-Medical Laboratories-Particular Requirements for Quality and Competence (Medical Laboratories: Particular requirements for quality and competence) $[4,5,6,7]$ and

- ISO 9001:2008 - Systems Quality Management (Applications). [8]

The past few years' public health laboratories in the Republic of Macedonia, following the world trends and the EU seek to introduce appropriate quality standards, so reliable test results, and protect the population from unsafe: food, water, air, soil, items that come into contact with food, pharmaceuticals, cosmetics and others. [9,10]

In the Republic of Macedonia only review the number of accredited laboratories in accordance with the data of IARM: according to ISO/IEC 17025 standard has 43 testing laboratories and 7 calibration laboratories; and in accordance with ISO 15189 has two private laboratories. Certified according to ISO 9001:2008 is more, taking into account the private companies that perform certification (data from April 2014). [11]

Monitoring and implementation of quality standards, which ensures the quality and validity of test results, $[12,13,14]$ and fulfilling the prerequisite criteria in terms of space, equipment and staff in public health laboratories in the country is an important requirement without which you cannot (sine qua non), regarding the use of the instrument for the assessment of health risk. $[15,16]$

\section{Objectives}

The main objective of this paper is determining the readiness of public health laboratories in the requirements (space, equipment and staff) in relation to the application of quality standards. To achieve this goal:

- Determining the current state of laboratories in terms of space, equipment and staff and the efforts of managers-doctors and managers-economists in relation to the implementation of quality standards in the Institute and the Centers for Public Health in the Republic of Macedonia.

- Commitment to the implementation and consistent application of these standards by the Institute and the Centers for Public Health in the Republic. Macedonia.

- Providing quality healthcare and standard of the population.

\section{Material and Methods}

This research was conducted through a questionnaire, which actually was the main instrument of research. It consists of 62 questions, relating to fulfillment of conditions (space, equipment and personnel) questions the commitment of the management team of the institutions, as well as issues that point to monitor management system. The survey included employees with a minimum higher education of the Institute of Public Health of the Republic and the remaining 10 Centers for Public Health in Macedonia, in the cities of Skopje, Bitola, Prilep, Ohrid, Tetovo, Kumanovo, Veles, Stip, Strumica, Kocani and two branches in Gostivar and Kavadarci.

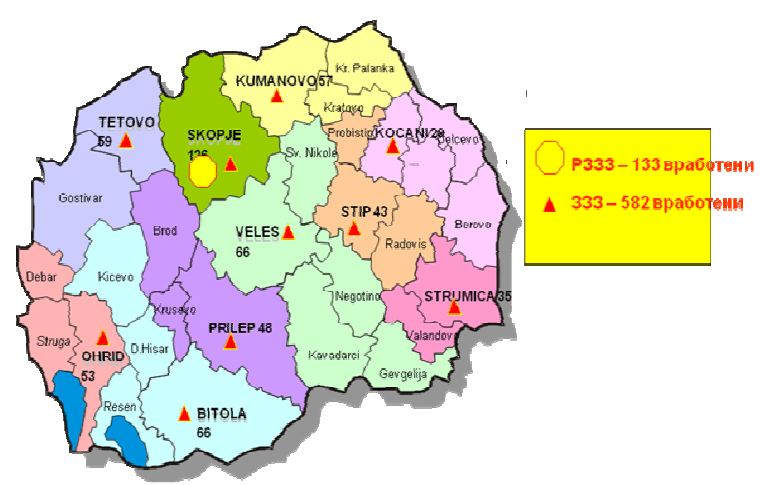

Figure 1. Network of Institutions of Public Health in the Republic of Macedonia.

The research study is the cross-section (transversal), which lasted 3 months and apply observational analytical method.

\section{Results and Discussion}

\subsection{Managers and Quality System}

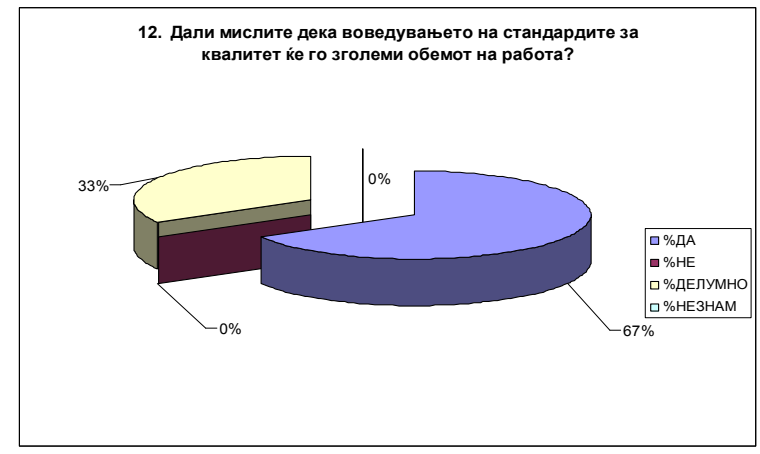

Chart 1. Connection between the introduction of quality standards and increased workload, according to managers - economists.

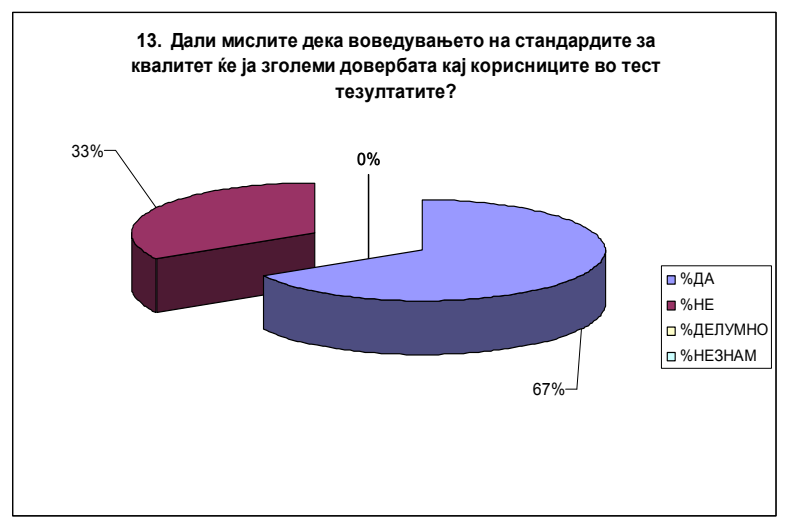

Chart 2. Connection between the introduction of quality standards and confidence in the test results, according to managers - doctors. 
The majority of respondents or $66.7 \%$ think that the introduction of quality standards will reduce public health risks, and significantly smaller proportion of managers economists $(33.3 \%)$ think that the public health risk is reduced partially.

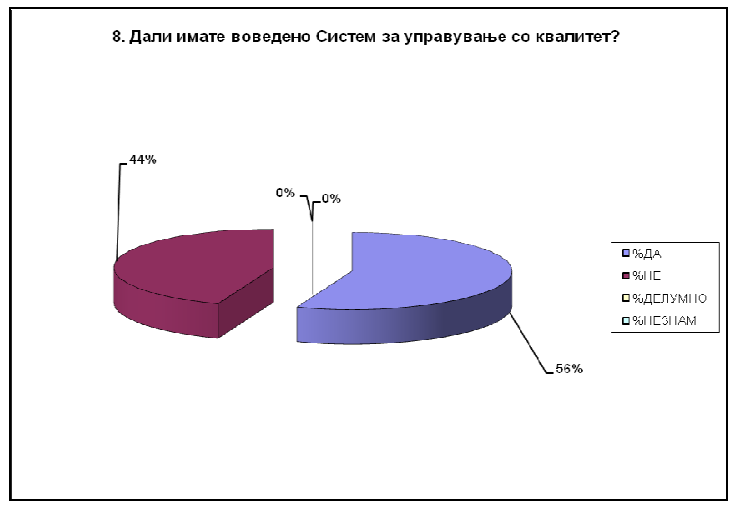

Chart 3. System Quality Management.

Any accredited public health facility, and those under preparation for accreditation have introduced a system of quality management, which means that they have and use documentation prepared in accordance with specific standards and adhere to the same requirements. System quality management implemented $55.6 \%$ of public health laboratories, and in $44.4 \%$ of them management team and other employees not heard of this term.

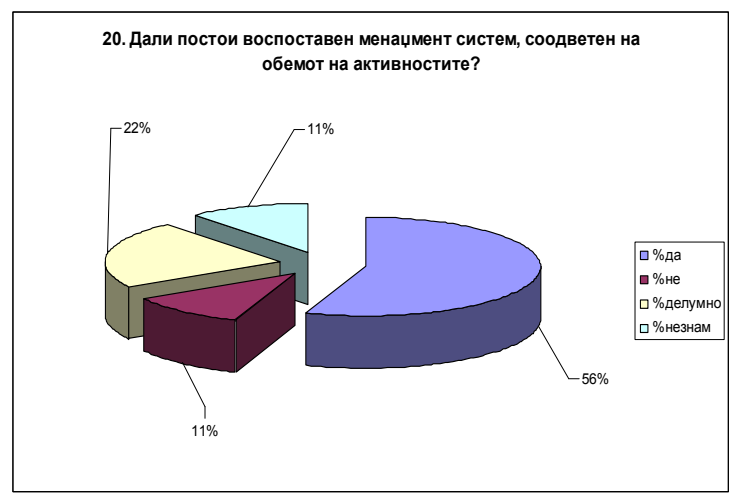

Chart 4. Management system appropriate to the scope of activities.

Nearly half, or $55.6 \%$ of the surveyed managers - health workers believe management system, or system of quality management is the appropriate scope of activities that are carried out in their laboratories, and $11.1 \%$ of the respondents consider the opposite. A majority $(22.2 \%)$ of the surveyed managers - health workers feels they have partial compliance management system with the scope of activities that are carried out in their laboratories, and only $11.1 \%$ of respondents did not heard management system.

\subsection{Equipment}

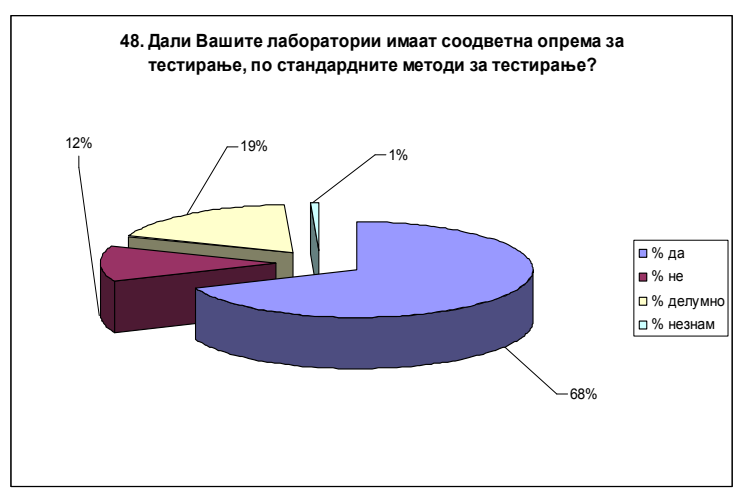

Chart 5. Test equipment in accordance with standard test methods.

Modern development of analytic practice and allow the use of modern equipment in performing the tests, which produce valid test results.

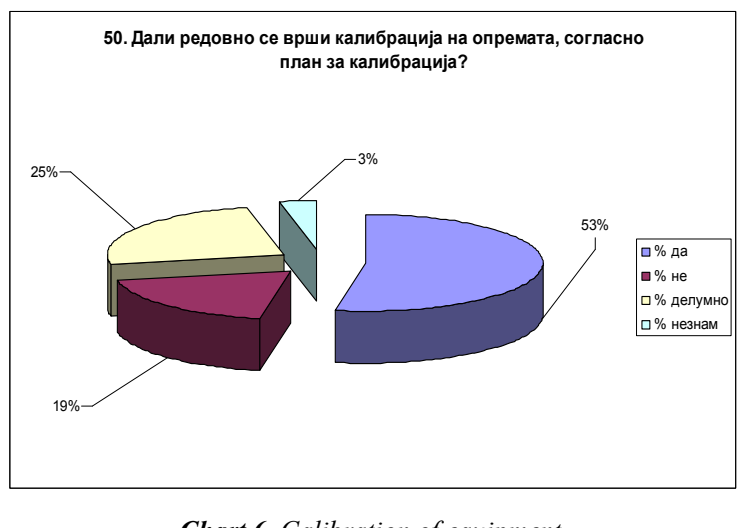

Chart 6. Calibration of equipment.

At only $52.8 \%$ of the measuring equipment in public health laboratories performed regular verification. $25 \%$ of the equipment is calibrated in appropriate and unsuitable firms that do not possess a certificate of calibration. $18.8 \%$ of the equipment is calibrated and verified, although its calibration and traceability is one of the essential criteria for accreditation of a laboratory. 3.4\% of respondents did not know the requirements and procedures for calibration or verification of measuring and auxiliary equipment in laboratories.

\subsection{Ambient Conditions}

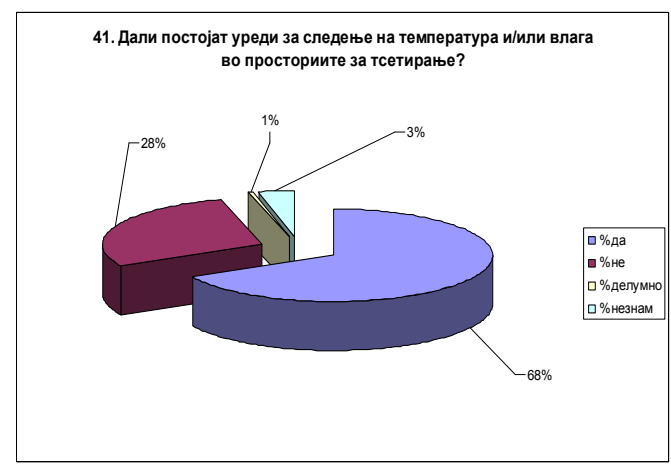

Chart 7. Monitoring of ambient conditions in laboratories for testing. 
Ambient conditions, monitoring of temperature, humidity, pressure, etc., which are needed for proper preparation of samples for their testing, and proper use of equipment is controlled in $67.4 \%$ of public health laboratories and most of the accredited and smaller part in those laboratories that are preparing for accreditation. In $28.5 \%$ of laboratories did not follow the conditions of the environment in which the tests are conducted, nor keep records of such activities. There is a small proportion of respondents (mostly from non-accredited laboratories) and $3.5 \%$ who had heard of such requests system quality of laboratory operations.

\subsection{Personal}

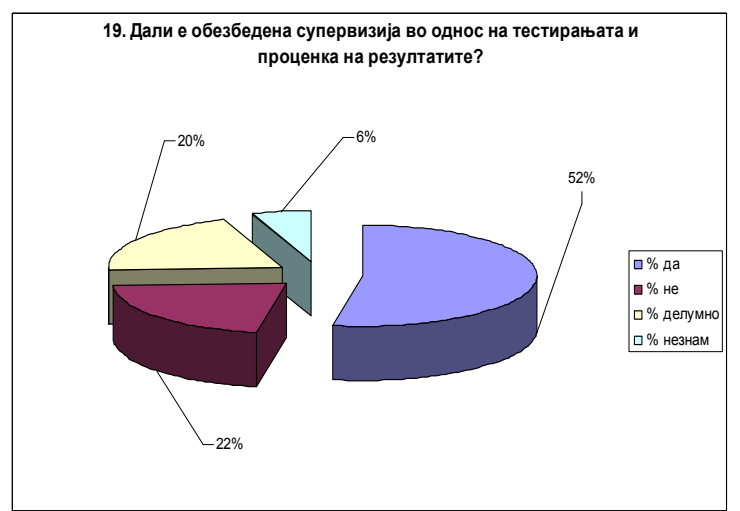

Chart 8. Supervision of staff performing tests and evaluating the results of tests.

Newly recruited or reassigned staff need to have adequate internal training, and after that time to perform tasks, especially tests under the supervision of senior staff from the area. This application of quality standards are implemented in $52.8 \%$ of public health laboratories, the $21.5 \%$ is not implemented, and in $20.1 \%$ of the laboratories were conducted surveillance test activities, but no documented records of such activities.

\section{Conclusions}

1. Certificate of accreditation according to ISO/IEC 17025 have: Institute of Public Health of the Republic of Macedonia and the regional centers for public health from: Tetovo, Kocani, Kumanovo, Bitola, Veles, Strumica, Ohrid, Stip and Skopje. Two public health centers have received certification according to ISO 9001 and in 2009 one of the centers certificate is revoked. Accreditation of medical laboratories in the Republic. Macedonia, according to the standard ISO 15189 has a two private laboratory.

2. We observed substantial differences in the attitude of the management and knowledge regarding the introduction of quality systems between managershealth professionals and managers-economists. Two thirds of managers-economists believe that the introduction of quality systems in public health laboratories will increase the workload and increase confidence in test results among users. Almost $90 \%$ of managers-health professionals think that the introduction of quality standards in public health laboratories will increase the workload and increased confidence in test results and reduce public health risk.

3. Adequate and modern equipment, in accordance with test methods have testing laboratories of the Institute of Public Health of the Republic and a small number of public health centers, which are only part of the full coverage with sophisticated equipment (CPH-Bitola, Kumanovo and Skopje).

4. The staff is competent, impartial and responsible for such tests, and the release of test results. What is missing is the motivation of the staff by management teams. The laboratory staffs lack training, especially external and proper allocation of training, the training in order to cover the entire staff.

5. The survey found that the willingness of public health laboratories in the country in terms of conditions (space, equipment and staff), the application of quality standards, taken globally considered as PARTIAL. Research has shown that the current state of laboratories in terms of space, equipment and staff in relation to the implementation of quality standards in the Institute and the Centers for Public Health in the Republic of Macedonia and varies significantly different between accredited and non-accredited public health laboratories.

\section{References}

[1] Drake G. Objectives and Roles of Accreditation and Certification of Laboratories, Accred Qual Assur 2003; 8: 441.

[2] Barker R, Wichmann B. Guidance for Accredited Laboratories. Accred Qual Assur 1999; 4: 287-98;

[3] International Organization for Standardization (ISO). ISO/IEC 17025:2005 General Requirements for the competence of testing an calibration laboratories.

[4] International Organization for Standardization (ISO). Quality Management for Medical Laboratory. (ISO/FDIS 15189). ISO: Geneva.

[5] Loeber JG Slagter S. Code of practice for implementation of a quality system in laboratories in the health care sector. 2nd rev. ed. Bilthoven: CCKL secretariat, 1995. PO box 392, 3720 AJ Bilthoven, The Netherlands.

[6] Jansen RTP, Kenny D, Blaton V, Burnett D, Huisman W, Plebani M, Queralto JM, Zerah S, van Lieshout J. Usefulness of EC4 Essential Criteria for Quality Systems of Medical Laboratories as Guideline to the ISO 15189 and ISO 17025 Documents. Clin Chem Lab Med 2000; 38: 1057-64.

[7] WHO Office for the Eastern Mediterranean, Series 3 „Principles of Management of Health Laboratories,", Alexandria, Egyp, 1993

[8] International Organization for Standardization (ISO). ISO 9001:2008 Quality Management Systems (Requirements). 
[9] Engelhard T, Feller E, Nizri Z. A Comparison of the Complimentary and Different Issues in ISO/IEC 17025 and OECD GLP. Accred Qual Assur 2003; 8: 208-12.

[10] Jacobson S. Accreditation of Calibration Laboratories to Normative Documents: Diversity or Standardization. Accred Qual Assur 2004; 9: 427-8.

[11] http://www.iarm.gov.mk

[12] Visser R. Standardization News: NEN 7777 Standardization of the Validation Process. Accred Qual Assur 2001; 6: 327-9.
[13] Stuart M, Squirrell A, Basley L. Reference Material Requirements for Laboratories and the Role of Accreditation Bodies. Accred Qual Assur 2004; 9: 209-14.

[14] Fishbach R. Metrological Demands of ISO 17025 on Testing Laboratiries. Accred Qual Assur 2001; 6: 41.

[15] http://www.publichealth.lacountry.gov

[16] http://www.ilac.org. 